\title{
Stepping in and stepping up: Responding to diversity and expressions of social exclusion from across the globe
}

2019 has seen increasing numbers of people take to the streets around the world in response to a diverse range of social issues relating to freedoms, human rights, environmental concerns and rising inequalities. These campaigns of disruption reflect a growing frustration with decision-makers who are perceived to be unwilling or unable to act in ways that preserve and enhance social well-being, but rather uphold the interests of the few and powerful. In this context, the Journal of Social Inclusion is pleased to feature research from around the world highlighting experiences of social exclusion and the need to promote more socially cohesive and inclusive communities.

Sociologists have long taught us that humans prefer to be surrounded by people 'like us'. More recently researchers have found corroborating evidence that our friends tend to have similar or complementary genotypes too (Christakis \& Fowler, 2014). In a world where mass migration is increasingly leading to greater cultural and linguistic diversity, concordantly we are seeing threats emerge in relation to how the public embraces such diversity including people of different faiths, socio-economic status, sexuality, gender identities and/or political persuasions, among other characteristics. This underscores the need for strong community leadership that reflects and responds to this diversity, both within and across countries, to not only reduce prejudice against those who are 'not like us', but moreover, to actively promote social cohesion and societal wellbeing which requires the genuine participation of all groups within societies. In the absence of this leadership, or even more worryingly, in the presence of leadership which may seek to capitalise on population differences, this edition shines a light on the complexities, challenges and opportunities in this space from diverse settings across the globe.

The first research article featured in this issue uses panel data methodology to analyse trends across 187 nations and demonstrates the inherent challenges humans have in relating to and embracing difference across populations. Although Amin acknowledges that diversity is key to the sustainable development of nations, the article explicitly confronts the challenges of diversity particularly, ethnic and/or religious diversity, through the lens of economic and social participation and population wellbeing more broadly. As a result of the rigorous analyses undertaken, it is impossible to escape the persistent positive relationship evident between diversity and social exclusion across the world, and the conclusion that this needs to be redressed in order to reduce the inherent tensions and growing likelihood of social and political unrest. As Amin acknowledges, diversity will not and cannot be reduced, and deliberate strategies and actions are therefore required to increase equality opportunity for all and promote social cohesion. In this context, some examples are identified by the researcher which provide some ways forward and may offer hope.

Continuing this edition's international focus, the second article in this issue examines experiences of social exclusion in the Arab world. Makhoul, Taket, Khoury and KabakianKhasholian review study findings from three studies exploring the experiences of Palestinian and Iraqi refugees in Lebanon, the support for women in labour in public hospitals in Egypt, Lebanon and Syria, and university scholarship recipients in Lebanon, respectively. The results are thematically analysed and applied through the lens of social exclusion and a grounded theory approach. Although each of these study findings highlight both unique and common features of social exclusion, a socio-ecological framework is used to identify global structural determinants of exclusion, in particular, for people affected by war and poverty. The researchers argue these supranational determinants are largely ignored or overlooked and as a result have used their findings to adapt the socio-ecological framework of social exclusion developed by Makhoul et al. (2009). 
The experience of homelessness can be one of the most profound forms of social exclusion. Our third article observes access to health and social services for a group of women experiencing homelessness in Ontario, Canada by Van Berkum and Oudshoorn. The unique nature of homelessness for women including the on-going hidden nature of such homeless is highlighted as is the need for improved service delivery models in the sector to better meet the needs of women. Employing a PhotoVoice method of data collection and grounded in a critical feminist, intersectional approach the authors foreground the stories and experiences of the women through various participatory processes. Participants were facilitated to represent their experiences from their own perspective via a number of mediums. Using data collected from photos, group discussions and interviews with a small group of women with lived experience of homelessness $(n=6)$, we read how these women view the barriers and facilitators (physical, social, economic and otherwise) to their negotiation of social spaces and service. Themes of exclusion and feeling on the 'margins' of society or being 'forgotten' emerge through the photos of street signs, empty buses and phone booths. The lack of connection and discrimination that comes from marginalisation is palpable. Signs proclaiming 'private property no trespassing' and 'no loitering' and locked doors are viewed here by the women within the context of a broader society where they are both hyper visible yet often ignored or hidden. Themes of inclusion and welcome are also found in the safety of some services and the flexibility of the programs and support offered there. New participatory models are emerging to elevate these voices, representation, resistance and access points to genuinely change the conversation and help us understand and take action in relation to what is truly needed to achieve social inclusion.

The potential for music to enhance social inclusion is explored in the article by Rinta Tettey. Rinta Tettey posits that Uganda's rich cultural musical history along with the embedded nature of music in Ugandan life is being underutilised as a means for engaging young people in their communities. Indeed, music is seen as an activity within the Ugandan context that possesses a unique capacity to bridge socio-economic and other divides, in part, reflected by the current high rates of youth unemployment. The researchers suggest that participation in music may have the ability to increase a sense of belonging and connection with community along with potentially providing a pathway to meaningful employment. Using findings from survey and interview data gathered from adults working in education in Eastern Uganda $(n=122)$, current gaps in the provision of music education in Uganda are identified and used to argue for increased support for music as a means of promoting social inclusion and employment opportunity. Once again, this article draws our attention to the opportunities for social inclusion that are grounded in community priorities and practices and where the means for participation and empowerment are culturally relevant, meaningful and accessible.

The final paper in this edition presents the results of an American study, by Ho and Browers, on the perceptions of inclusion and diversity experienced by business students $(n=349)$ at a rural university in west-central Michigan. Indeed, this article demonstrates the central role that education providers have in shaping inclusive attitudes and the ability to work with others as part of preparing the workforce of the future. The quantitative results indicate that most students perceived that the business school was supportive of diverse groups of students , irrespective of their gender; in contrast to the researcher's a priori expectations about potential gender differences. Although the results were overall supportive, additional qualitative feedback indicated some less acceptance when the issues related to non-physical disabilities, psychological conditions and issues of race and white supremacy. In addition to noting areas where further improvements are required, the researchers recognise the need for further monitoring and review activities to inform continuous improvement activities, particularly, 
awareness programs that promote the importance of diversity and inclusion. As demonstrated in the first article in this issue, we know that activities that actively seek to promote social cohesion are vital in a world where diversity is on the rise. To this end, the leadership taken by this business faculty in a rural university in Michigan, USA, serves as a model for other institutions and settings around the world.

\section{Paul Harris, PhD \\ Editor}

\section{Angella Duvnjak, PhD \\ Co-Editor}

\author{
School of Human Services and Social Work \\ Griffith University \\ Australia
}

\title{
References
}

Christakis, N. A. \& Fowler, J. H. (2014). Friendship and natural selection, PNAS July 22, 2014 (Supplement 3) 10796-10801; https://doi.org/10.1073/pnas.1400825111

Taket, A., Crisp, B., Nevill, A., Lamar, G., Graham, M., Barter-Godfrey, S. (2009). Theorising social exclusion. UK: Routledge. 